\title{
The effect of multilingualism, sociobiographical, and situational factors on communicative anxiety and foreign language anxiety of mature language learners
}

\section{Jean-Marc Dewaele}

\author{
Birkbeck, University of London
}

\begin{abstract}
The present study focuses on individual differences in levels of communicative anxiety (CA) and foreign language anxiety (FLA) in the first (L1), second (L2), third (L3) and fourth (L4) language of 106 adult language learners. Data were collected about CA/FLA levels when speaking with friends, with strangers, and speaking in public. The analyses revealed that multilinguals do experience more CA in stressful situations in their L1, but that levels of FLA are higher in languages learnt later in life. The knowledge of more languages was linked to lower levels of FLA in the L2. Female participants were only found to experience higher levels of CA in L1 public speech. Older participants tended to report higher levels of CA/FLA across languages. Rank orders for CA/FLA were significantly similar across the L1, L2, L3, and L4, which suggests that levels of CA/FLA are relatively stable and could be linked to a lower order personality trait such as emotional intelligence.
\end{abstract}

\section{Key words}

age

individual

differences

number of

languages known

second language learning

$\operatorname{sex}$

\section{Introduction}

Yaprak Uygur, a young female PhD student (Turkish L1, English L2) made the following observation in response to one of the open questions in the web questionnaire on emotion and bilingualism (Dewaele \& Pavlenko, 2001-2003):

While speaking Turkish I feel more relaxed and it is easier for me to express myself. But in English I feel anxious and get tired because I need to think all the time the right words to say.

The anxiety that Yaprak Uygur refers to has been labeled Foreign language anxiety (FLA) and has been defined as: "the feeling of tension and apprehension specifically associated with second language contexts, including speaking, listening, and learning." (MacIntyre \& Gardner, 1994, p. 284). 
This FLA typically develops in the foreign language classroom. Horwitz, Horwitz and Cope (1986) report the words of a student: "When I'm in my Spanish class I just freeze! I can't think of a thing when my teacher calls on me. My mind goes blank" (p. 125).

Where do these feelings of tension and apprehension originate? Guiora (1983) suggested that "the task of learning a new language is a profoundly unsettling psychological proposition" because it threatens the learner's self-concept and worldview (p. 8). Yaprak Uygur's statement suggests that her FLA arises from the tiresome constant need to "think the right words." From this we can infer that Yaprak Uygur's L2 production is not yet proceduralized (i.e., relying on implicit linguistic competence) and therefore relies heavily on explicit, declarative knowledge (Paradis, 2004). This relatively onerous cognitive process raises Yaprak Uygur's awareness that a moment of inattention might lead to an interruption of her L2 speech production or to an error. This awareness of "walking near the edge" might make her feel tense and apprehensive, in other words, cause her FLA.

The frustration experienced by the novice L2 learner or L2 user is brilliantly described by Eva Hoffman (1989), reflecting on her experiences as a young Polish immigrant in Canada:

I am enraged at the false persona I'm being stuffed into, as into some clumsy and overblown astronaut suit. I'm enraged at my adolescent friends because they can't see through the guise, can't recognize the light-footed dancer I really am (1989, pp. 118-119).

Although much research has been done on FLA, it remains one of the tantalizing enigmas in multilingualism and Second Language Acquisition research. FLA is complex and multidimensional: It is partly related to an individual's personality, partly related to situational factors (formality of situation, number, sex, and identity of interlocutors) and partly linked to more general socioeducational and political factors (Dörnyei, 2005; Young, 1991).

FLA is an enigma that merits to be cracked because "the potential of anxiety to interfere with learning and performance is one of the most accepted phenomena in psychology and education" (Horwitz, 2000, p. 256). Indeed, FLA has been shown to be a significant predictor of oral achievement (Woodrow, 2006). It is therefore necessary to understand why a language learner feels anxious in order to control such anxiety and alleviate its effects (MacIntyre \& Gardner, 1991a,b). High levels of FLA in the classroom cause negative affective reactions and can induce negative attitudes and discourage students from continuing their language study (Philipps, 1991, 1992). Research on FLA has potentially strong pedagogical implications and many researchers have argued that foreign language teachers should learn to recognize explicit anxiety-indicating cues, so as to identify learners who struggle with high levels of FLA (Gregersen, 2007; Horwitz, 1996; Young, 1991, 1992). The consequences of FLA extend beyond the classroom. A person who has studied a second language (L2) till graduation but suffers from high levels of FLA may actually never speak the L2 after leaving school. This is a shame for the individual and for the whole school system that has invested money, time, and energy in the teaching of a skill that will ultimately not be used. It would also have economic consequences for the individual in many countries where active multilingualism is a prerequisite for well-paid jobs, and it could ultimately affect the economy as a whole 
(Mettewie, van Mensel, \& Belang, 2006). Finally, the non-use of the L2 may also have political consequences in bilingual countries where the ability of using the L2 is perceived by members of the L2 community as a sign of goodwill towards them.

\section{Rationale for the present study}

The present study originated from the following three observations:

(1) most research on $\mathrm{CA} / \mathrm{FLA}^{1}$ has focused on young learners (from childhood to late teenage years), relatively little research has focused on older L2 learners and L2 users.

(2) most studies on CA/FLA have considered a single foreign language of learners, very few have considered CA/FLA in both the native language and multiple foreign languages.

(3) no research so far has considered the effect of the number of languages known on CA/FLA (with the exception of Dewaele, Petrides, \& Furnham, 2008).

The present study aims to identify a number of sociobiographical and situational variables affecting levels of CA/FLA among mature foreign language learners and users.

\section{Previous research}

\section{1 \\ Conceptual and methodological issues}

Research on FLA started in the 1970s (Curran, 1976; Gardner, Smythe, Clément \& Gliksman, 1976; Kleinmann, 1977; Scovel, 1978). MacIntyre (2007) observes that "SLA researchers have settled on the idea that language anxiety is an emotional experience uniquely provoked by L2 situations" (Horwitz, Horwitz, \& Cope, 1986). MacIntyre and Gardner (1989) attributed inconsistencies in the early research in this area to "an inappropriate level of instrument specificity" (p.272). This view seems to have evolved, as MacIntyre (2007) now argues that the initial contradictory findings on the link between success in SLA and FLA (as reported in MacIntyre, 1999 and in Scovel, 1991) would be due to a confusion in levels of abstraction, more specifically the distinction between trait anxiety, situation-specific anxiety and, and state anxiety, "each of which provides a valuable, but somewhat different perspective on the processes under study" (p.565).

Traits refer to stable, general patterns of behavior. In other words, an individual with a high level of trait anxiety is likely to feel anxious in a variety of situations. Spielberger (1983) developed a Trait Anxiety Scale that was not specifically designed for language production and that showed no consistent link with L2 variables (MacIntyre \& Gardner, 1989, 1994a).

At the situation-specific level of conceptualization, "the concern is for concepts that are defined over time within a situation" (MacIntyre, 2007, p. 565). The Foreign

1 In the present paper we will use the abbreviation CA/FLA when referring to the anxiety of communicating in all languages, including the first language (L1) of multilinguals. The term 'foreign language anxiety' will be used when referring to specific communicative anxiety in the use of a foreign language. 
Language Classroom Anxiety Scale (FLCAS) developed by Horwitz et al. (1986) measures this situation-specific anxiety. For Horwitz and colleagues FLA is "a distinct complex of self perceptions, beliefs, feelings, and behaviors related to classroom learning arising from the uniqueness of the language learning process" (Horwitz et al., 1986, p. 128). Researchers who used the FLCAS found it quite reliable. Negative correlations emerged between scores on the FLCAS and measures of L2 performance (Aida, 1994; Horwitz, 1986, 2001; Rodriguez \& Abreu, 2003).

Finally, at the state level, "the concern is for experiences rooted in a specific moment in time without much concern for how frequently those experiences occurred in the past or whether they might occur again in the future" (MacIntyre, 2007, p. 565). Second language performance seems negatively correlated with higher levels of state anxiety (Gregersen, 2003; MacIntyre \& Gardner, 1994b). MacIntyre (2007) speculates that there are fewer studies on state anxiety in SLA because of the complicating factor that learners attempt "to cope with and compensate for the effects of anxiety" (p.565). Also an automatic process of habituation lessens the negative emotional arousal over time. An example of such state FLA is described in Dörnyei and Kormos (2000). The authors found that participants with low levels of FLA could momentarily experience higher levels of FLA with interlocutors who were much less confident in the L2. The interlocutor with a higher level of FLA would pull the less anxious speaker along (Dörnyei \& Kormos, 2000, p. 296).

Dewaele (2002) raised the question whether the stability of FLA could be related to the fact that the studies in question considered only individuals with one foreign language (Cheng, Horwitz, \& Schallert, 1999; Horwitz, 1986; MacIntyre \& Charos, 1996; MacIntyre \& Gardner, 1991a,b, 1994; Onwuegbuzie, Bailey, \& Daley, 1999). A second possible reason for the apparent stability of FLA is that all studies so far were cross-sectional in design. In other words, FLA as measured at one point in time. Sometimes synchronic variation was measured by inquiring about FLA levels in different situations, but not diachronic variation. The most frequently used design is quasi-longitudinal, where FLA scores of participants in different year groups are compared (cf. MacIntyre, Baker, Clément \& Donovan, 2002; Saito \& Samimy, 1996). The only study to have used a real longitudinal design is van Daele's (2007). The author looked at fluctuations in FLA in French L2 and English L3 of Flemish students (Dutch L1) over a nearly two-year period. The effects of FLA on lexical richness and grammatical accuracy in both languages faded and disappeared completely at the last data collection point (van Daele, 2007).

\section{2}

\section{Psychological and sociobiographical factors associated with FLA}

Seo, Barrett, and Bartunek (2004) have demonstrated how core affective feelings of pleasure or displeasure may influence the direction of behavioral outcomes (choice of behavior) in a work environment. Though the foreign language classroom is not a typical work environment, it does share some important characteristics with it such as the setting of a goal level and a goal commitment. Seo et al. (2004) showed that people in positive feeling states are more likely to focus on exploring and obtaining anticipated positive outcomes (Seo et al., 2004, p.430). On the other hand, people in negative affective states engage in more effortful, piecemeal information processing 
(Seo et al., 2004, p.429). They also focus more on avoiding and preventing possible occurrences of negative outcomes, also labeled 'a defensive behavioral orientation' (Seo et al., 2004, p.430). Feelings of displeasure and fear are obstacles in foreign language learning: reciprocal paths seem to exist between language anxiety and motivation. High levels of motivation abate anxiety, and high levels of anxiety inhibit motivation, which in turn affects progress in foreign language learning (Dewaele, 2005; Gardner et al., 1976; Gardner \& MacIntyre, 1993).

Onwuegbuzie et al. (1999) examined the effect of 26 factors on FLA. The authors identified seven variables that significantly predict FLA (i.e., age, academic achievement, prior history of visiting foreign countries, prior high school, experience with foreign languages, expected overall average for current language course, perceived scholastic competence, and perceived self-worth). These variables account for $40 \%$ variance in FLA (Onwuegbuzie et al., 1999, p. 232).

Dewaele, Petrides and Furnham (2008) investigated the effects of trait emotional intelligence and sociobiographical variables (age, sex, education level, number of languages known, age of onset of acquisition, context of acquisition, frequency of use, socialization, network of interlocutors, self-perceived proficiency) on CA in the first, and FLA in the second, third, and fourth languages of 464 multilingual individuals, in five different situations (speaking with friends, colleagues, strangers, on the phone, and in public). Data were collected via web-based questionnaires (Dewaele \& Pavlenko, 2001-2003). A consistent pattern of results emerged across languages and situations. Sex and education levels had no significant effects on CA/FLA. Higher levels of trait emotional intelligence corresponded to significantly lower levels of CA/FLA. Even in conditions involving only low levels of CA/FLA (such as communication with friends in the L1), the Low trait emotional intelligence group always showed the highest CA/FLA levels. The authors concluded that the constellation of emotion-related self-perceptions that trait emotional intelligence encompasses is inversely related to CA/FLA levels. Age of onset of acquisition was also inversely linked to FLA: early starters in the L2 and L3 suffered less from FLA. Participants who had made regular extracurricular use of a foreign language during the learning of that language also reported lower levels of FLA than participants whose instruction had been purely classroom-based. A higher frequency of use of the foreign language, a stronger socialization in that language, a larger network of interlocutors and a higher level of self-perceived proficiency in a language were also linked to lower levels of CA/FLA.

Dewaele (2002) analyzed the psychological and sociodemographic correlates of FLA in French L2 and English L3 of 100 Flemish students. Both societal and individual contexts were found to determine levels of FLA. Students from lower social classes reported higher levels of FLA in French but not in English. This unexpected finding was linked to the fact that French used to be a prestige language in Flanders and functioned as a social marker. This social effect appeared to be a stronger predictor of FLA in French than three personality variables (extraversion, neuroticism, and psychoticism) which explained only $9 \%$ of the total variation. Psychoticism, extraversion, and, to a lesser extent, neuroticism, did however significantly predict levels of FLA in English L3 production, explaining $20 \%$ of the total variation. Higher levels of extraversion and psychoticism were linked to significantly lower levels of FLA in English. Lower levels of 
neuroticism correlated with lower levels of FLA in English. The same pattern emerged for FLA in French but it was not significant. It was argued that the higher FLA of the introverts follows logically from the observation that they tend to be reserved, quiet, and unassertive in contrast to the more outgoing and talkative extraverts (Furnham \& Heaven, 1998). The extraverts' more optimist side might limit their fear of embarrassment when speaking a foreign language. They also felt more competent in English L3. The study further showed that general trait anxiety (as measured by the Neuroticism-scale) and FLA might usually be considered as orthogonal dimensions, but that a moderate positive relationship emerged between both in that study.

A second study on the same population focused on the link between attitudes and FLA in English L3 and French L2 (Dewaele, 2005). According to their FLA scores in French and their FLA scores in English, participants were categorized as low, intermediate or high FLA in French, with a separate categorization for FLA in English. Participants reporting low levels of FLA in French L2 were found to have significantly more positive attitudes towards French than the participants who reported intermediate levels of FLA and the participants with high levels of FLA. Although a similar pattern emerged for English L3, the difference between the three FLA groups was not significant (Dewaele, 2005).

\section{3}

\section{Sex differences}

Barrett, Lane, Sechrest and Schwartz (2000) studied sex differences in the complexity and differentiation of people's representation of emotional experience. They noted that the empirical status of sex differences in emotion remains unresolved.

Women consistently describe themselves as more emotionally intense than do men when emotionality is defined as a global disposition largely independent of the social context (Barrett et al., 2000). However, the differences are less clear-cut when emotionality is defined as the experience of a specific emotion in a specific social context. Barrett, Robin, Pietromonaco, and Eyssell (1998) asked participants to provide global, retrospective descriptions of their emotional characteristics at an initial session, and then provided momentary emotion ratings as well as details about the social context in which they experienced their emotions over a one-week period. A comparison between the male and female participants showed significant differences on the global self-descriptions but not in the averaged momentary ratings of emotion. The authors also found that the sex of the interaction partner elicited sex differences in emotionality; participants experienced and expressed more emotion when in opposite-sex dyads (p. 555).

Barrett reports that only half of the studies on this topic report sex differences in fear or anxiety, anger, depression, or sadness. These differences are "typically in the stereotypic direction" (Barrett et al., 2000, p. 1027). Some researchers suggest that there are sex differences in emotional experience, primarily linked to differential socialization experiences, others suggest that differences are inconsistent and exist mainly for emotional expressions (Barrett et al., 2000, p. 1027). 


\section{4}

\section{Age effects}

Studies on the link between age and CA/FLA yield inconsistent results. Donovan and MacIntyre (2005) did find higher FLA scores in French among Anglo-Canadian university students compared to high school and junior school pupils (p. 424). MacIntyre et al., (2002) reported higher levels of L1 English CA among younger (grade 8) AngloCanadian junior high school students in French immersion programes compared to grade 9 pupils but no difference between the grade levels for FLA in French (p. 550). Dewaele, Petrides and Furnham (2008) found significant negative correlations between age of adult multilinguals and their CA/FLA scores, suggesting that older participants suffered less from CA/FLA. The finding confirmed van Daele's (2007) findings and contradicts the prevalent view in the literature that FLA does not decrease as learners become more advanced (Onwuegbuzie et al., 1999; Saito \& Samimy, 1996).

\section{5}

\section{Number of languages known}

Individuals who know more languages have been found to develop more grammatical metalinguistic awareness (Kemp, 2001) and become better at learning additional languages. Kemp (2007) found that participants knowing more than two languages (and up to 12) used significantly more grammar learning strategies. Dewaele et al. (2008) found that participants with knowledge of more languages, reported lower levels of CA/FLA in some situations in the L1 and L2, and in more situations in the L3 and L4. The authors speculated that the relative weakness of the effect in the L1 and L2 is linked to the fact that regular use means that speakers are less likely to have to mobilize all their resources to produce the L1 or L2. However, when producing a language learnt later in life, in which one typically feels less proficient, one may feel like entering relatively uncharted linguistic waters. Knowing more languages may give multilinguals a little bit more confidence in their ability to avoid linguistic icebergs (Dewaele et al., 2008).

\section{6}

\section{Native language skills as predictor of FLA}

Several researchers suggest that the learning of an L2 is based primarily on one's ability to learn one's native language (e.g., language aptitude) (Ganschow \& Sparks, 1996; Sparks, Artzer, Ganschow, Siebenhar, Plageman, \& Patton, 1998; Sparks \& Ganschow, 1991):

Students who have overt or subtle native-language difficulties in reading, writing, listening, and speaking are likely to experience similar difficulties in learning a foreign language (Sparks et al., 1998, p. 209).

These researchers argue that FLA does not play a causal role in individual differences in foreign-language learning, as MacIntyre and Gardner (1991b) argue, but is merely the consequence of their L1 learning difficulties. Also, students' learning ability would be a confounding variable in the study of the impact of affective differences on L2 learning (Sparks, Javorsky, Patton, \& Ganschow, 1998). 


\section{Rationale for the present study}

Trait theorists argue that personality is hard-wired, biologically based and influenced by culture in the sense that behaviors are expressed according to local norms. Personality traits are thus considered stable when similar scores emerge in test-retest procedures over long periods. This stability can be affected by trauma, brain damage, or very consistent exposure to stimuli. The present study will investigate whether CA/FLA can be considered a stable personality trait by extending the analysis cross-sectionally to anxiety in speaking the L1, L2, L3, and L4 in three situations.

The purpose of the current study is also to investigate the effect of situation and sociodemographic variables (sex, age, and number of languages known to the speaker) on levels of CA/FLA among mature language learners. We will focus more specifically on CA when speaking the native language and foreign languages, as this is generally considered to be the most anxiety-provoking of second-language activities (MacIntyre \& Gardner, 1991a; Phillips, 1992; Young, 1990).

\section{Method}

\section{1 \\ Participants}

The participants included 106 students enrolled in Access, BA and MA courses in the School of Languages, Linguistics and Culture at Birkbeck, University of London. The sample consisted of 61 females and 45 males. The ages of the participants ranged from 18 to $75(M=38.4, S D=12.0)$. Participants with an age below the mean were categorized as "younger" $(n=60)$; those with an age above the mean were categorized as "older" $(n=44)$.

Fifty-one participants had English as an L1; 10 had Spanish and nine French as an L1. Other L1 s included Albanian, Arabic, Catalan, Creole, Dari, Dutch, German, Greek, Gujarati, Italian, Japanese, Kinyarwanda, Kurdish, Lingala, Lugwere, Mina, Persian, Portuguese, and Wolof. All the students were fluent in English and were living in the London area. Fifty-one students had French as an L2, 41 has English as an L2. Other L2s included Akan, German, Kimbundu, Portugese, Russian, Serbo-croatian, Spanish, Shiluba, and Welsh. The most frequent L3s were French $(n=19)$, German $(n=14)$, English $(n=12)$, Spanish $(n=12)$, Italian $(n=7)$. Some students also had Creole, Portuguese, Romanian, and Swahili as an L3. The most frequent L4s included Spanish $(n=9)$, German $(n=8)$, French $(n=7)$, Italian $(n=6)$. There were also single cases of Hebrew, Hindi, Japanese, Swahili, Swedish, and Turkish as L4.

The sample thus consists of 35 bilinguals, 33 trilinguals and 38 quadrilinguals. Nine students also knew a fifth language but they were categorized as quadrilinguals for methodological reasons. The words 'bilingual', 'trilingual' and 'quadrilinguals' are clearly used as blanket terms and do not refer to proficiency levels (cf. Hoffmann, 2001; Sia \& Dewaele, 2006). Some of the participants had learned their foreign languages in instructed settings while others had learned them in naturalistic conditions. The 
questionnaire merely asked what languages they knew and the order of acquisition. There is no information concerning the level of proficiency in the various languages.

\section{2}

\section{Materials}

Participants completed a sociodemographic questionnaire based on Baker (1992) relating to language background, age, sex, level of CA/FLA in the different languages known to the participant in three situations. The question was formulated as follows: (1) "How anxious are you using your L1/L2/L3/L4 when speaking with friends? (2) ... when speaking to strangers? ... when speaking in public?"

CA/FLA was measured with a five-point Likert response format. The range was as follows: 1) not anxious; 2) a little anxious; 3) anxious; 4) very anxious; 5) extremely anxious.

\section{Hypotheses}

1. CA/FLA levels will be lowest in the L1 and will grow progressively from the L2, to the L3, to the L4.

2. CA/FLA levels will be lowest talking to friends, they will be at an intermediate level when speaking to strangers, and will be highest when talking in public.

3. CA/FLA levels will be lower among participants knowing more languages.

4. CA/FLA levels will be lower among males (i.e., following the stereotype of the more "emotional" female).

5. CA/FLA levels will be lower among older participants.

6. CA/FLA scores in the L1, L2, L3 and L4 will be positively correlated.

\section{Results}

Two-tailed $t$-tests and one-way analyses of variance (ANOVA) were used to test the different hypotheses.

\section{1}

\section{CA /FLA in L1, L2, L3, and L4}

We found as predicted that CA levels are lowest in the L1 and increase gradually from the L2 to the L3 and to the L4. A paired $t$-test revealed that speaking the L1 with friends, with strangers and in public is significantly less anxiety-provoking than speaking the L2 in these three situations, $t(104)=-10.95, p<.0001 ; t(105)=-8.51, p<.0001$, and $t(103)=-9.51, p<.0001$, respectively $)^{2}$.

2 Some participants did not provide complete answers, hence the slight variation in the number of participants per group. 
A similar paired $t$-test revealed that speaking the $\mathrm{L} 2$ with friends, with strangers and in public is significantly less anxiety-provoking than speaking the $\mathrm{L} 3, t(67)=-4.93$, $p<.0001 ; t(67)=-4.66, p<.0001$ and $t(64)=-4.95, p<.0001$, respectively.

The difference between FLA when speaking with friends and strangers in the L3 and FLA in the L4 is no longer significant, $t(36)=-1.5, p=n s$ and $t(35)=-1.29, p=n s$ respectively). Speaking the $\mathrm{L} 4$ in public does remain more anxiety-provoking than speaking the $\mathrm{L} 3$ in public however, $t(35)=-2.14, p<.04$. The mean scores are presented in Figure 1.

\section{Figure 1}

CA/ FLA levels in the L1, L2, L3, and L4

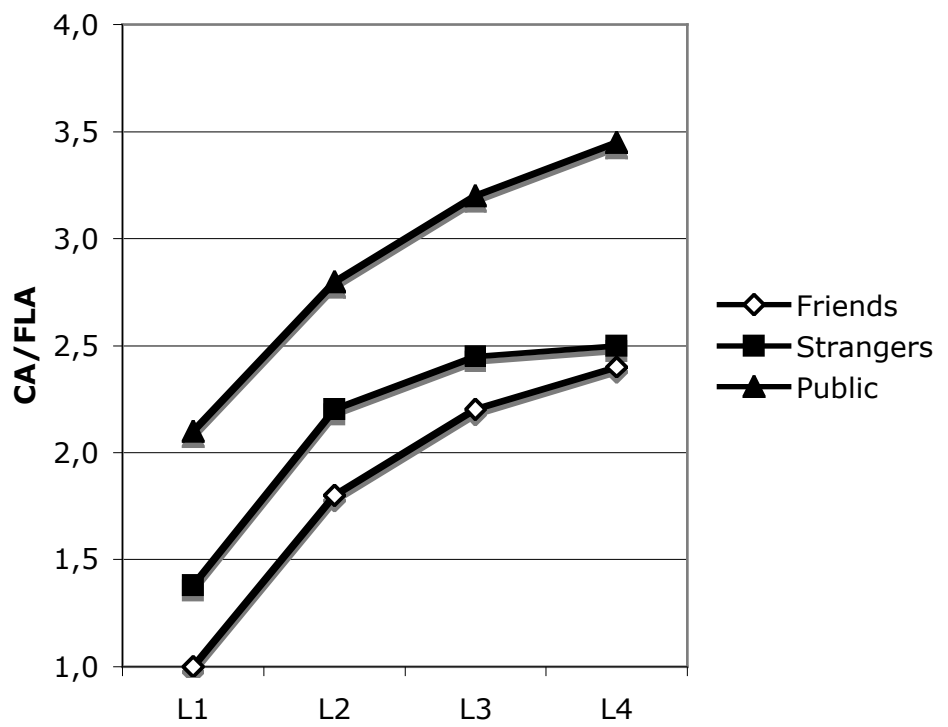

\section{2}

\section{Effect of situation}

A series of paired $t$-tests was used in order to determine the effect of the situation on levels of CA/FLA. Mean values for the different situations in the different languages are displayed in Figure 2. CA levels in the L1 where found to be significantly lower for talking with friends than talking with strangers, $t(104)=-4.78, p<.0001$, which was, in turn, less anxiety-provoking than speaking in public, $t(104)=-6.61, p<.0001$. The same pattern appeared in the $\mathrm{L} 2$ with talking to friends judged to be less anxiety-provoking than talking to strangers, $t(105)=-3.91, p<.0002$, which was, in turn, less anxietyprovoking than speaking in public, $t(103)=-7.21, p<.0001$. Similarly for speaking in the L3, talking to friends was judged to be less anxiety-provoking than talking to strangers, $t(67)=-2.16, p<.035$, which was, in turn, less anxiety-provoking than speaking in public, $t(64)=-6.82, p<.0001$. FLA in the L4 was not lower in talking to friends than to strangers, $t(36)=0 ., p=n s$, but it was considered less anxiety-provoking than speaking in public, $t(36)=-6.27, p<.0001$. 


\section{Figure 2}

The effect of situation on CA/ FLA levels in the L1, L2, L3, and L4

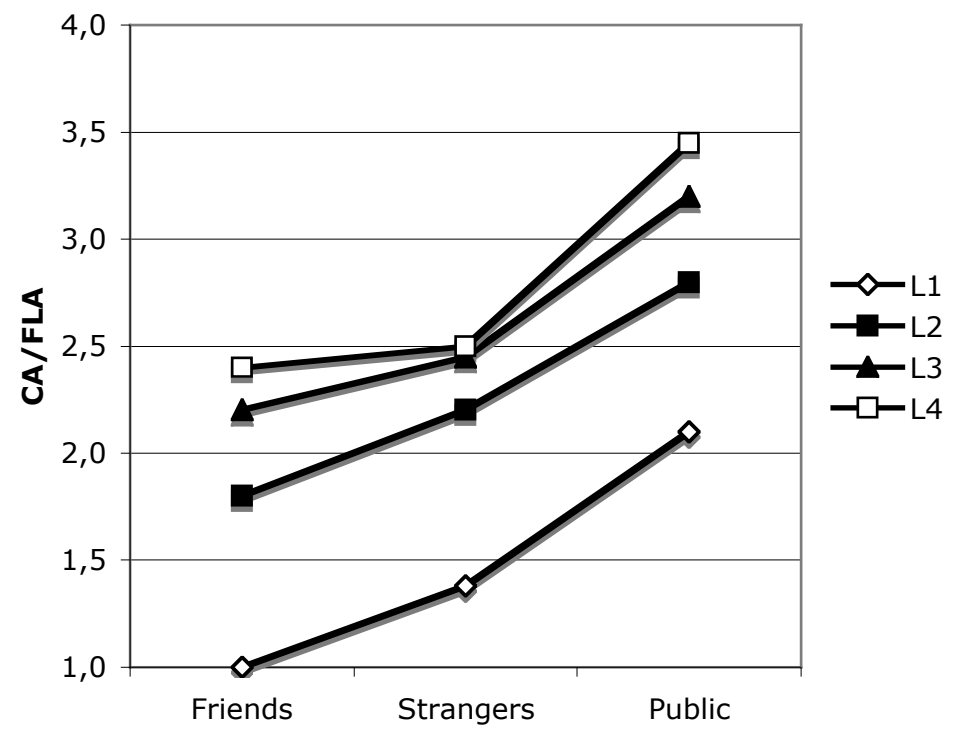

\section{3}

\section{Effect of sex}

An independent $t$-test revealed no differences in anxiety levels between the 45 male and the 61 female participants in speaking with friends in the L1, $t(104)=-1.16, p=n s$, the L2, $t(104)=-1.04, p=n s$. The picture was similar for the 28 males and 48 females speaking the L3, $t(66)=0.27, p=n s$, and the 13 males and 25 females speaking with friends in the $\mathrm{L} 4, t(35)=.72, p=n s$.

Sex did not have an effect on CA/FLA levels with speaking with strangers in the L1:, $t(104)=1.01, p=\mathrm{ns}$, the L2, $t(104)=-.9, p=n s$, the L3, $t(66)=.83, p=n s$, and the L4, $t(35)=.72, p=n s$.

A significant difference in CA levels between males and females did emerge when speaking in public in the L1, $t(103)=2.55, p<.012$. The effect weakens in the L2, $t(102)=1.56, p=.12$, and disappears completely in the L3, $t(63)=.75, p=n s$, and the L4, $t(34)=.95, p=n s$.

The results for public speech are presented in Figure 3.

\section{4}

\section{Effect of age}

A number of independent $t$-tests with age of the participant as grouping variable ('younger' vs. 'older') revealed no differences on CA levels when speaking the L1 to friends, $t(102)=1.17, p=n s$, to strangers, $t(102)=.41, p=n s$, or in public, $t(102)=-.54, p=n s$.

The younger group tended to feel less anxious when speaking the L2 to friends, $t(102)=-1.93, p<.056$, this tendency weakened when talking to strangers, $t(102)=-1.33$, $p=\mathrm{ns}$, or in public, $t(100)=-1.25, p=n s$, (see Figure 4). 


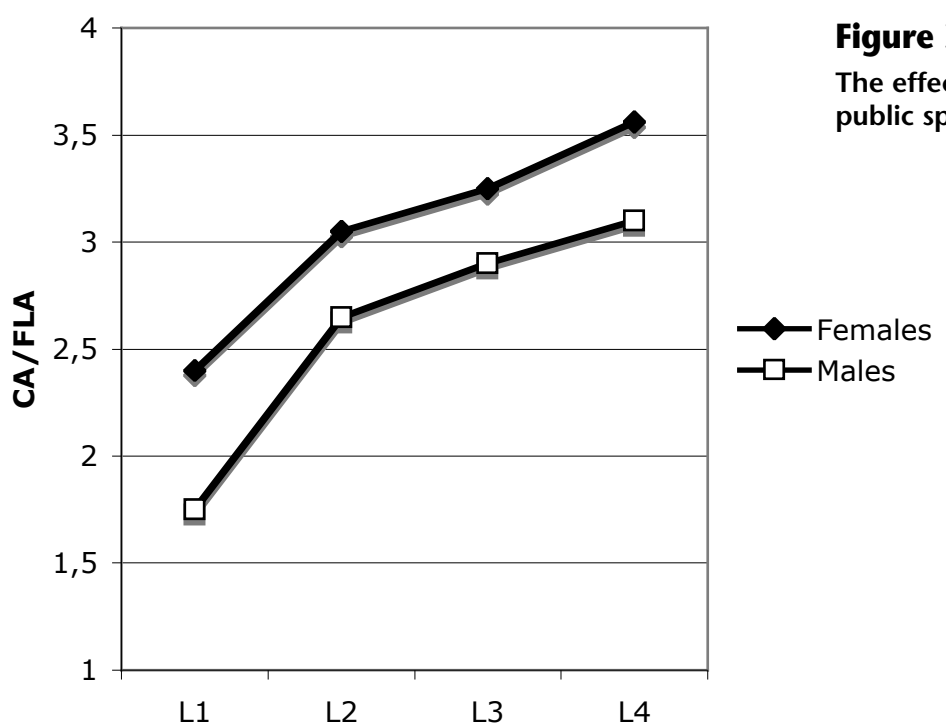

Similar patterns emerged in the L3 (younger $(n=41)$ vs. older $(n=26)$ ), they were not significant when speaking to friends in the L3, $t(65)=-1.46, p=n s$, but became significant when talking to strangers, $t(65)=-2.73, p<.008$, and weakened again in public speech, $t(62)=-1.28, p=n s$, (see Figure 4).

Independent $t$-tests revealed no differences in FLA levels between younger and older participants (younger $(n=21)$ vs. older $(n=15))$ when speaking the L4 to friends, $t(34)=0.51, p=n s$, to strangers, $t(34)=.02, p=n s$, or in public, $t(34)=.35, p=n s$.

Results for the L2 and the L3 are presented in Figure 4.

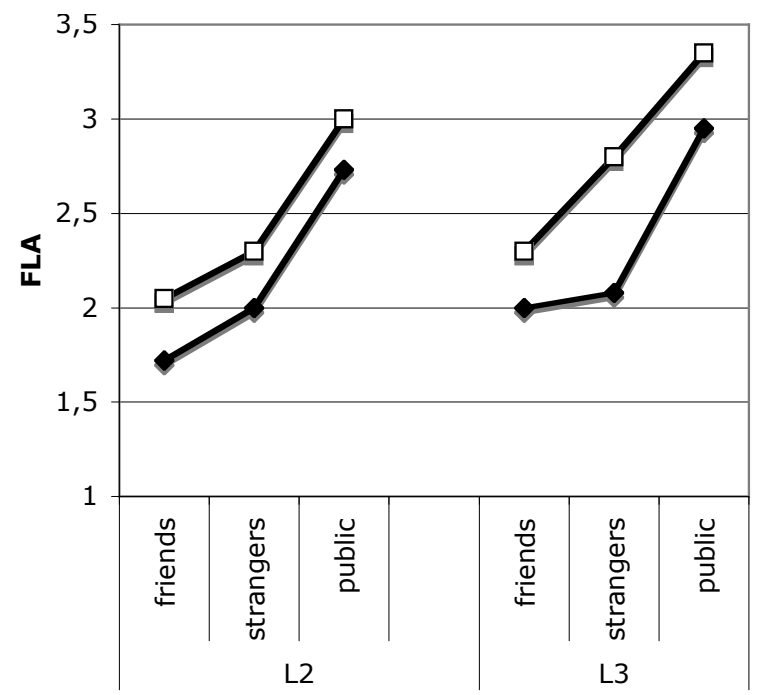

\section{Figure 4}

The effect of age on FLA in public speech in the L2 and the L3

\section{$\multimap$ Younger}

$\rightarrow-$ Older 


\section{5}

\section{Effect of number of languages known}

A one-way ANOVA with number languages known to the participant as main effect revealed no significant effect on CA levels when speaking the L1 to friends, $F(2,103)=1.1$, $p=n s$; to strangers, $F(2,103)=.85, p=n s$; or in public, $F(2,103)=.54, p=n s$. Fisher's PLSD post hoc test revealed no significant differences between the three groups.

A significant effect of number languages known to the participant on levels of FLA did emerge in the L2 when speaking to friends, $F(2,103)=4.16, p<.032$. A Fisher's PLSD post hoc test revealed that the difference between the bilinguals and the quadrilinguals is significant $(p<.008)$, as well as between the bilinguals and the trilinguals $(p<.035)$, but not between the trilinguals and the quadrilinguals. A similar pattern emerged for speaking the $\mathrm{L} 2$ to strangers, $F(2,103)=3.6, p<.03$. Here also, the Fisher's PLSD post hoc test showed a significant difference between the bilinguals and the quadrilinguals $(p<.009)$, a marginal difference between the bilinguals and the trilinguals $(p<.092)$, and no difference between the trilinguals and the quadrilinguals. The same pattern is repeated for speaking the $\mathrm{L} 2$ in public, $F(2,101)=3.48, p<.035$. A Fisher's PLSD post hoc test showed that the difference between the bilinguals and the quadrilinguals is significant $(p<.013)$, but only marginally so between the bilinguals and the trilinguals $(p<.056)$, and not significant between the trilinguals and the quadrilinguals. The results for the L2 are presented in Figure 5.

To compare FLA levels in speaking the L3 between trilinguals and quadrilinguals 2-tailed paired $t$-tests were used. These revealed only non-significant differences. Speaking with friends, $t(65)=0.68, p=n$ s, with strangers, $t(65)=-.64, p=n s$, and in public, $t(63)=.38, p=n s$, was not more anxiety-provoking in the L4 than in the L3.

\section{Figure 5}

The effect of number of languages known on FLA levels in the L2

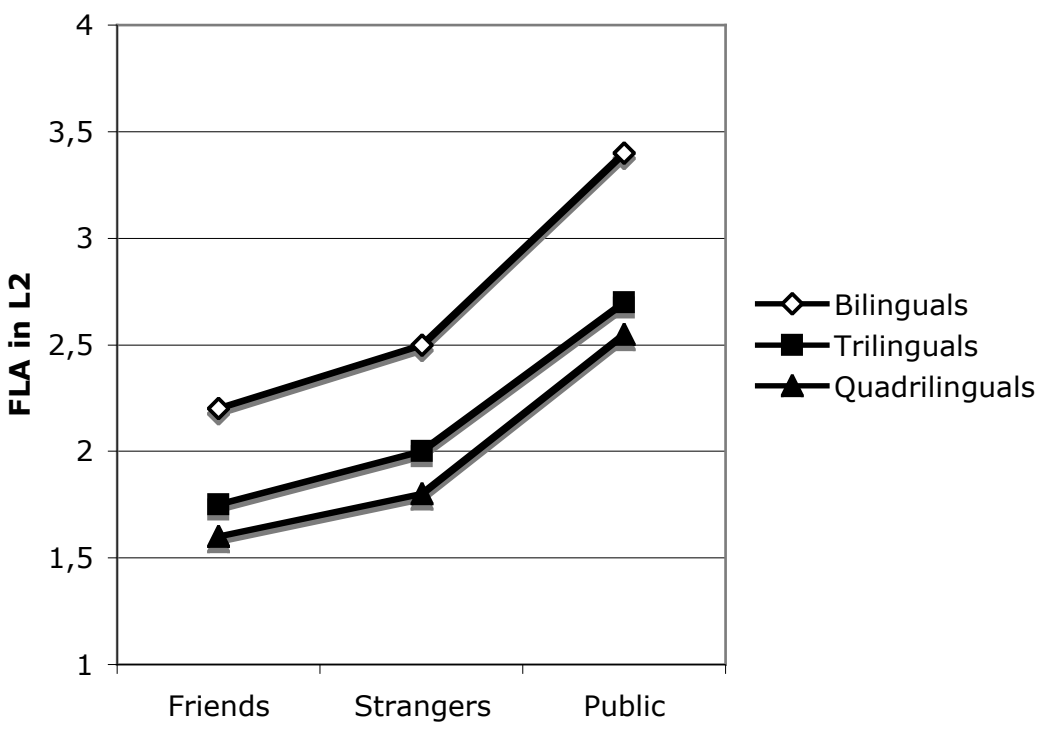




\section{6}

\section{The link between CA / FLA scores in the L1, L2, L3, and L4}

The sum of CA/FLA scores for the three situations was calculated for every participant in the three languages. These aggregate CA/FLA measures were subjected to a series of Spearman rank analyses. It revealed highly significant positive correlations between CA/FLA levels in the L1 and the L2 (Rho $(105)=0.63, p<.0001)$, between the $\mathrm{L} 2$ and the $\mathrm{L} 3($ Rho $(69)=0.68, p<.0001)$ and between the L3 and the L4 $(R h o(37)=0.79, p<.0001)$. These results suggest that the ranking of participants according to CA/FLA levels is very similar in the different languages. Given the wide variety of L1 s in our sample, it was impossible to assess proficiency levels in the $\mathrm{L} 1$, and hence the link between proficiency and CA. The strong correlations between CA/FLA levels in the four languages do not allow us to identify a cause, which could be very well be an underlying psychological or cognitive dimension.

\section{Discussion}

Studies on CA/FLA in foreign language production, typically report higher levels of anxiety in speaking the L2 compared to the L1. Dewaele et al. (2008) also found a significant increase in FLA for languages learnt later in life across situations. This finding was confirmed in the present study. The effect was significant when comparing the L2 to the $\mathrm{L} 1$, the $\mathrm{L} 3$ to $\mathrm{L} 2$ but it was much weaker when comparing the $\mathrm{L} 4$ to the $\mathrm{L} 3$. The differences in CA/FLA levels are thus strongest between L1 and L2 and gradually weaken in languages learnt subsequently. One possible explanation for the gradually higher FLA levels in languages learnt later is that participants are typically most proficient in the languages that were acquired earlier and used most frequently. Had our population consisted of English L1 speakers only, the curve may have been much steeper. However, the large proportion of non-English L1 speakers could have diluted the effect because English might have been their L2, or L3 or L4 but it probably was the language they used most frequently in their daily life in London. Dewaele et al. (2008) found that frequency of use of a language is a strong predictor of CA/FLA in that language. Our non-English participants could thus be expected to report lower levels of FLA in English as a result of ongoing socialization in this language.

The situation was found to affect levels of CA/FLA in the L1, L2, L3, and partially in the L4. Private speech with friends is less anxiety-provoking that interaction with strangers. Public speech is the most anxiety-provoking activity, especially if it is done in a foreign language. This pattern also emerged in Dewaele et al. (2008).

Trilinguals and quadrilinguals are generally less anxious when speaking their L2 than bilinguals. One possible explanation for this is that trilinguals and quadrilinguals have become better communicators as a result of their multilingualism (cf. Baker, 2000) and that their self-confidence, as well as their self-perceived competence has grown as a result. The effect does not extend to FLA levels in the L3 however, where trilinguals and quadrilinguals experienced similar levels of FLA.

The effect of sex on CA/FLA levels was absent in private speech situations in the different languages. Women did not experience higher levels of CA/FLA when speaking with friends or strangers. This finding is congruent with Barrett et al.'s (2000) observation that no difference in emotionality emerges between men and women when the question is 
linked to a specific social context, as was the case in the present study. The only significant sex effect was found in public speech situations in the L1 where female participants reported higher levels of CA. The difference was non-significant in the languages learnt later in life. This phenomenon cannot be explained by socioeconomic factors, as all the students were in full employment when they filled in the questionnaires and participants from both sexes occupied positions across the socioprofessional spectrum. The cause could be of a sociocultural nature, for example that women are judged more severely when speaking in public. This could lead to an increased level of CA in that specific situation (cf. Pavlenko, 2001). Coleman (1996) also found indications that female students were more embarrassed by their mistakes in the $\mathrm{L} 2$ in public speech situations.

The effect of age on CA was unexpected as it contradicts the finding reported in Dewaele et al. (2008) that older participants reported significantly lower levels of CA/FLA. It does, however, reflect the patterns in Donovan and MacIntyre (2005) where participants over age 18 reported higher levels of FLA than those under 18. One possible explanation for the unexpected finding in the present study could be the fact that the more mature students at Birkbeck have learnt their foreign languages in a very different educational environment. Grammar-based language teaching put the accent much more on the written language and much less on the oral interaction which has become the norm in modern communicative teaching methods. The attitude towards the making of errors has also changed dramatically over the years. Communicative approaches put the accent on communicative competence more than on a grammatical accuracy (Stern, 1992). The younger generation may therefore feel much more relaxed about communication in a foreign language that they might not yet completely master.

The research question relating to the stability of CA/FLA remains open as the results can be interpreted in two directions. It could be argued that CA/FLA is a stable personality trait as anxiety levels were found to be highly correlated across the languages known to the participants. CA/FLA levels varied in intensity but rank orders remained significantly similar across languages. Someone who is highly anxious in speaking the L1 will also be highly anxious in speaking the L2, the L3, and the L4.

However, one could also argue that CA/FLA is not stable. Indeed, it was found to vary according to situational, sociodemographic, and biographical variables and was previously found to co-vary with basic personality dimensions (cf. Dewaele, 2002; Dewaele et al., 2008). Moreover, CA/FLA levels in a particular language may change over short periods if the individual is involved in intensive language-learning and gains self-confidence and self-perceived competence. Van Daele (2007) also found that FLA in an L2 and an L3 varied over a two-year period. The strong synchronic variation on the CA/FLA scale is in sharp contrast with the position of an individual on one of the Big Five major personality trait dimensions ${ }^{3}$. This position may slowly evolve according to age, and may be sex-specific (with younger and female subjects being more extraverted for example) but the position on any personality dimension remains constant in any situation (an introvert will not be more introvert in a particular situation) although social and linguistic behavior may vary (Furnham \& Heaven, 1998).

CA/FLA is probably situated half-way between trait, situation-specific anxiety and state, more sensitive to environmental factors than personality traits and yet more

3 Extraversion, Neuroticism, Openness, Agreeableness and Conscientiousness. 
stable than states since it remains relatively stable across languages. The fact that rank orders of participants were highly comparable across the three situations suggests that FLA is more than just a situation-specific CA.

The finding of the positive correlation between CA/FLA levels in the L1 and the L2 could also be interpreted as support for the idea that deficits in the L1, leading to higher levels of CA, are carried over to the L2, L3, and L4 (Sparks, Javorsky, Patton, \& Ganschow, 1998).

To sum up, the findings of this study partially support Hypothesis 1 (CA/FLA is lower in languages acquired earlier), fully support Hypothesis 2 (CA/FLA levels are highest when talking in public, followed by talking to strangers and finally talking to friends in any known language), partially support Hypothesis 3 (the more languages one knows the less anxious one becomes), offer very partial support for Hypothesis 4 (women experience higher levels of CA/FLA, but only in L1 public speech), reject Hypothesis 5 (older participants report higher levels of CA/FLA) and could be interpreted as support for Hypothesis 6 (CA/FLA rank orders remain similar across different languages, although they are subject to strong synchronic variation).

\section{Conclusion}

CA/FLA may no longer be the enigma it once was, its fluid and multidimensional nature guarantees its past, present, and future reputation as a very "slippery" variable. As MacIntyre (2007) pointed out, CA/FLA can be conceptualized at different levels: trait anxiety, situation-specific anxiety and state anxiety. The stability of CA/FLA levels such as they were measured in this study could be related to the fact that they referred to relatively generic situations (i.e., trait anxiety and situation-specific anxiety) rather than very specific situations (discussing a specific topic in the $\mathrm{L} 2$ with one unique interlocutor) that may generate variable levels of state anxiety. The relative stability of CA/FLA in the different languages may also result from it being linked to trait emotional intelligence (Dewaele et al. 2008), which is situated higher up in the hierarchy of personality traits (Petrides, Pita, \& Kokkinaki, 2007).

One important contribution of the present study is to have shown that although FLA levels in the L2, L3, and L4 are significantly higher than CA levels in the L1, the latter do vary across situations. Speaking in public in the L1 elicits a level of CA that is comparable to FLA elicited by speaking to strangers in the L2.

The finding that an individual's CA/FLA levels are determined by a combination of independent variables is not new in itself. It does highlight the need to include a large range of variables linked to psychological, sociobiographical, and situational factors. One such independent variable that had not been included in previous research designs (with the exception of Dewaele et al., 2008) is the number of languages known to the speaker. Knowing more languages seems to lower FLA, at least in the L2.

More research in CA/FLA is clearly needed, especially longitudinal research into variation in CA/FLA involving multiple foreign languages, to understand the tortuous evolution of CA/FLA in foreign language learners and users. 


\section{References}

AIDA, Y. (1994). Examination of Horwitz, Horwitz and Cope's construct of foreign language anxiety: The case of students of Japanese. The Modern Language Journal, 78, 155-168.

BAKER, C. (1992). Attitudes and language. Clevedon: Multilingual Matters.

BAKER, C. (2000). A parents' and teachers' guide to bilingualism. Clevedon: Multilingual Matters.

BARRETT, L. F., LANE, R., SECHREST, L., \& SCHWARTZ, G. (2000). Sex differences in emotional awareness. Personality and Social Psychology Bulletin, 26, 1027-1035.

BARRETT, L. F., ROBIN, L., PIETROMONACO, P. R., \& EYSSELL, K. M. (1998). Are women the "more emotional sex?" Evidence from emotional experiences in social context. Cognition and Emotion, 12, 555-578.

COLEMAN, J. A. (1996). Studying languages: A survey of British and European students. London: CILT.

CHENG, Y., HORWITZ, E. K., \& SCHALLERT, D. L. (1999). Language anxiety: Differentiating writing and speaking components. Language Learning, 49, 417-446.

CURRAN, C. A. (1976). Counselling-learning in second languages. Apple River, IL: Apple River Press.

DEWAELE, J.-M. (2002). Psychological and sociodemographic correlates of communicative anxiety in L2 and L3 production. The International Journal of Bilingualism, 6, 23-39.

DEWAELE, J.-M. (2005). Sociodemographic, psychological and politico-cultural correlates in Flemish students' attitudes toward French and English. Journal of Multilingual and Multicultural Development, 26, $118-137$.

DEWAELE, J.-M., \& PAVLENKO, A. (2001-2003). Web questionnaire on bilingualism and emotion. University of London.

DEWAELE, J.-M., PETRIDES, K. V., \& FURNHAM, A. (2008). The effects of trait emotional intelligence and sociobiographical variables on communicative anxiety and foreign language anxiety among adult multilinguals: A review and empirical investigation. Language Learning, 58 (4).

DONOVAN, L. A., \& MACINTYRE, P. D. (2005). Age and sex differences in willingness to communicate, communication apprehension and self-perceived competence. Communication Research Reports, 21, 420-427.

DÖRNYEI, Z. (2005). The psychology of the language learner. Individual differences in second language acquisition. Mahwah, NJ: Lawrence Erlbaum.

DÖRNYEI, Z., \& KORMOS, J. (2000). The role of individual and social variables in oral task performance. Language Teaching Research, 4, 275-300.

FURNHAM, A., \& HEAVEN, P. (1998). Personality and social behaviour. London: Arnold.

GANSCHOW, L., \& SPARKS, R. (1996). Anxiety about foreign language learning among high school women. Modern Language Journal, 80, 199-212.

GARDNER, R. C., SMYTHE, P. C., CLÉMENT, R., \& GLIKSMAN, L. (1976). Social and psychological factors in second language acquisition. Canadian Modern Language Review, 32, $198-213$.

GARDNER, R. C., \& MACINTYRE, P. D. (1993). A student's contributions to second language learning: Part II. Affective variables. Language Teaching, 26, 1-11.

GREGERSEN, T. (2003). To err is human: A reminder to teachers of language-anxious students. Foreign Language Annals, 36, 25-32.

GREGERSEN, T. (2007). Breaking the code of silence: A study of teachers' nonverbal decoding accuracy of foreign language anxiety. Language Teaching Research, 11, 209-221.

GUIORA, A. Z. (1983). The dialectic of language acquisition. Language Learning, 33, 3-12.

HOFFMANN, C. (2001). Towards a description of trilingual competence. The International Journal of Bilingualism, 5, 1-17.

HOFFMAN, E. (1989). Lost in translation: A life in a new language. New York: Penguin Books.

HORWITZ, E. K. (1986). Preliminary evidence for the reliability and validity of a foreign language anxiety scale. TESOL Quarterly, 20, 559-562. 
HORWITZ, E. K. (1996). Even teachers get the blues: Recognizing and alleviating language teachers' feelings of foreign language anxiety. Foreign Language Annals, 29, 365-372.

HORWITZ, E. K. (2000). It ain't over 'til it's over: On foreign language anxiety, first language deficits and the confounding of variables. The Modern Language Journal, 84, 256-259.

HORWITZ, E. K. (2001). Language anxiety and achievement. Annual Review of Applied Linguistics, 21, $112-126$.

HORWITZ, E. K., HORWITZ, B., \& COPE, J. (1986). Foreign language classroom anxiety. The Modern Language Journal, 70(ii), 125-132.

KEMP, C. (2001). Metalinguistic awareness in multilinguals: Implicit and explicit grammatical awareness and its relationship with language experience and language attainment. Unpublished $\mathrm{PhD}$ thesis. University of Edinburgh.

KEMP, C. (2007). Strategic processing in grammar learning: Do multilinguals use more strategies? International Journal of Multilingualism, 4, 241-261.

KLEINMANN, H. H. (1977). Avoidance behaviour in adult second language learning. Language Learning, 27, 93-101.

MACINTYRE, P. D. (1999). Language anxiety: A review of the research for language teachers. In D. J. Young (Ed.), Affect in foreign language and second language teaching: A practical guide to creating a low-anxiety classroom atmosphere (pp. 24-45). Boston: Mc Graw-Hill.

MACINTYRE, P. D. (2007). Willingness to communicate in the second language: Understanding the decision to speak as a volitional process. The Modern Language Journal, 91, 564-576.

MACINTYRE, P. D., BAKER, S. C., CLÉMENT, R., \& DONOVAN, L. A. (2002). Sex and age effects on willingness to communicate, anxiety, perceived competence, and L2 motivation among junior high school French immersion students. Language Learning, 52, 537-564.

MACINTYRE, P. D., \& CHAROS, C. (1996). Personality, attitudes, and affect as predictors of second language communication. Journal of Language and Social Psychology, 15, 3-26.

MACINTYRE, P. D., \& GARDNER, R. C. (1989). Anxiety and second language learning: Towards a theoretical clarification. Language Learning, 39, 251-275.

MACINTYRE, P. D., \& GARDNER, R. C. (1991a). Methods and results in the study of foreign language anxiety: A review of the literature. Language Learning, 41, 25-57.

MACINTYRE, P. D., \& GARDNER, R. C. (1991b). Language anxiety: Its relationship to other anxieties and to processing in native and second language. Language Learning, 41, 513-534.

MACINTYRE, P. D., \& GARDNER, R. C. (1994a). The subtle effects of language anxiety on cognitive processing in the second language. Language Learning, 44, 283-305.

MACINTYRE, P. D., \& GARDNER, R.C. (1994b). The effects of induced anxiety on cognitive processing in computerised vocabulary learning. Studies in Second Language Acquisition, 16, 1-17.

METTEWIE, L., van MENSEL, L., \& BELANG, D. (2006). Entreprises bruxelloises et language étrangères. Pratique et coût d'une main d'oeuvre ne maîtrisant pas les langues étrangères. Rapport de recherche. Brussels: TIBEL ASBL.

ONWUEGBUZIE, A., BAILEY, P., \& DALEY, C. E. (1999). Factors associated with foreign language anxiety. Applied Psycholinguistics, 20, 217-239.

PARADIS, M. (2004). A neurolinguistic theory of bilingualism. Benjamins: Amsterdam-Philadephia.

PAVLENKO, A. (2001). Bilingualism, gender, and ideology. The International Journal of Bilingualism, $5,117-151$.

PETRIDES, K. V., PITA, R., \& KOKKINAKI, F. (2007). The location of trait emotional intelligence in personality factor space. British Journal of Psychology, 98, 273-289.

PHILLIPS, E. M. (1991). Anxiety and oral competence: Classroom dilemma. French Review, 65, $1-14$.

PHILLIPS, E. M. (1992). The effects of language anxiety on student oral test performance and attitudes. The Modern Language Journal, 76, 14-26.

RODRIGUEZ, M., \& ABREU, O. (2003). The stability of general foreign language classroom anxiety across English and French. Modern Language Journal, 87, 365-374. 
SAITO, Y., \& SAMIMY, K. K. (1996). Foreign language anxiety and language performance: A study of learner anxiety in beginning, intermediate, and advanced-level college students of Japanese. Foreign Language Annals, 29, 239-251.

SCOVEL, T. (1978). The effect of affect on foreign language learning: A review of the anxiety research. Language Learning, 28, 129-141.

SCOVEL, T. (1991). The effect of affect on foreign language learning: A review of the anxiety research. In E. K. Horwitz \& D. J. Young (Eds.), Language anxiety from theory and research to classroom implications (pp.15-23). Englewood Cliffs, NJ: Prentice Hall.

SEO, M.-G., BARRETT, L. F., \& BARTUNEK, J. M. (2004). The role of affective experience in work motivation. Academy of Management, 29, 423-439.

SIA, J., \& DEWAELE, J.-M. (2006). Are you bilingual? Birkbeck Studies in Applied Linguistics, $1,1-19$.

SPARKS, R.-L., ARTZER, M., GANSCHOW, L., SIEBENHAR, D., PLAGEMAN, M., \& PATTON, J. (1998). Differences in native-language skills, foreign-language aptitude, and foreign-language grades among high-, average-, and low-proficiency foreign-language learners: Two studies. Language Testing, 15, 181-216.

SPARKS, R.-L., \& GANSCHOW, L. (1991). Foreign language learning difficulties: Affective or native language aptitude differences? Modern Language Journal, 75, 3-16.

SPARKS, R.-L., ARTZER, M., PATTON, J., GANSCHOW, L., MILLER, K., HORDUBAY, D. J., \& WALSH, G. (1998). Benefits of multisensory structured language instruction for at-risk foreign language learners: A comparison study of high school Spanish students. Annals of Dyslexia, 48, 239-270.

SPIELBERGER, C. D. (1983). Manual for the state-trait anxiety inventory (form Y). Palo Alto, CA: Consulting Psychologists Press.

STERN, H. H. (1992). Issues and options in language teaching. Oxford: Oxford University Press.

Van DAELE, S. (2007). Linguïstische vlotheid, accuraatheid en complexiteit in de verwerving en de verwerking van een tweede taal [Linguistic fluency, accuracy and complexity in the acquisition and processing of a second language]. Unpublished $\mathrm{PhD}$ dissertation. Free University of Brussels.

WOODROW, L. (2006). Anxiety and speaking English as a second language. RELC Journal, $37,308-328$.

YOUNG, D. J. (1990). An investigation of students' perspectives on anxiety and speaking. Foreign Language Annals, 23, 539-553.

YOUNG, D. J. (1991). Creating a low-anxiety classroom environment: What does language anxiety research suggest? The Modern Language Journal, 75, 426-439. 